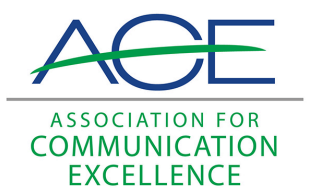

Journal of Applied Communications

\title{
The Art of Editing; The Importance of Mechanics in Journalistic Writing: A Study of Reporters and Editors; Trade Show Marketlng Idea Kit: A Hands-On Approach for Trade Show Marketers; Seeing is Remembering: How Visuals Contribute to Learning from Television News
}

Kurt R. Knebusch

Richard P. Carlson

Follow this and additional works at: https://newprairiepress.org/jac

(c) (1)(2)

This work is licensed under a Creative Commons Attribution-Noncommercial-Share Alike 4.0 License.

Recommended Citation

Knebusch, Kurt R. and Carlson, Richard P. (1991) "The Art of Editing; The Importance of Mechanics in Journalistic Writing: A Study of Reporters and Editors; Trade Show Marketlng Idea Kit: A Hands-On Approach for Trade Show Marketers; Seeing is Remembering: How Visuals Contribute to Learning from Television News," Journal of Applied Communications: Vol. 75: Iss. 1. https://doi.org/10.4148/ 1051-0834.1493

This Review is brought to you for free and open access by New Prairie Press. It has been accepted for inclusion in Journal of Applied Communications by an authorized administrator of New Prairie Press. For more information, please contact cads@k-state.edu. 
The Art of Editing; The Importance of Mechanics in Journalistic Writing: A Study of Reporters and Editors; Trade Show MarketIng Idea Kit: A Hands-On Approach for Trade Show Marketers; Seeing is Remembering: How Visuals Contribute to Learning from Television News

\author{
Abstract \\ Review of "The Art of Editing ," by Peter Jacobi in Folio; "The Importance of Mechanics in Journalistic \\ Writing: A Study of Reporters and Editors," by Steven A. Ward and Rick Seifert ; "Trade Show Marketlng \\ Idea Kit: A Hands-On Approach for Trade Show Marketers", Skyline Displays, Inc.; "Seeing is \\ Remembering: How Visuals Contribute to Learning from Television News," by Doris A. Graber.
}


Knebusch and Carlson: The Art of Editing; The Importance of M echanics in Journalistic W

"The Art of Editing," by Peter Jacobi in Folio:, (July 1990); The Hanson Publishing Group Inc., Stamford, Connecticut, pp. 102106. Folio, subtitled "The Magazine for Magazine Management," is published monthly by The Hanson Publishing Group Inc., 6 River Bend, Stamford, Connecticut, 06907-0949. Call 203-3589900 for subscription information or past issues.

Public-sector magazines often bog down in blandness. Limited resources coupled with an Ivory Tower ignorance of audience can lead to dry books full of inoffensive (read: unimportant) information. The result? Bored readers less-inclined to support your agency or institution.

But your magazine can resist and thrive. The answer, writes Peter Jacobi, journalism professor at Indiana University, lies in the art of editing. In other words: Write for the reader, serve fresh content and study your audience. As editor, your job is to "breathe life" into the publication.

Writing for the reader means writing for "thinking people," Jacobi explains. Targeting the lowest common denominator denigrates the audience and weakens the magazine's personality, he says. Instead, you should blend "the predictable and the surprising, the constant and the dynamic, the continuing and the innovative so the reader will be both comfortable and stimulated in the reading." Jacobi says editors should keep in mind that the reader comes first, not the editor or staff. And he recommends that editors develop, then work within, a flexible formula and editorial policy.

Each issue should offer fresh, comfortably challenging content, Jacobi says. To do so, the editor must keep ahead of changes in the field of coverage, society and the competition. Jacobi quotes the late A.C. Spectorsky, former Playboy editor, who said,"The successful publication leads its readership, rather than following it." A basic of journalism-the element of surprise, importance, or unusualness-is key, Jacobi notes. The goal is to separate your magazine from the rest of the pack, making it indispensable to the reader.

You make your magazine indispensable by knowing the reader's needs, Jacobi says. And you understand those needs by "searching outward" through reader research, he says. Jacobi promotes two methods: letters to randomly selected readers, and focus groups:

-Letters should be one or two pages of open-ended questions about your magazine. Mail them every few issues to a hundred readers; include a stamped, self-addressed envelope and a short note of explanation. Jacobi says the results will prove worthwhile: "Readers will feel honored to be asked. You'll get a high response rate. And you'll learn as editor what those folks out there are thinking."

-Focus groups pool a half dozen random readers over lunch or in a discussion session. Again, ask open-ended questions: "What do you expect from this magazine? Do you need this publication, and why? What does it do better than the competition?" Always seek specifics, Jacobi adds.

Jacobi, a former magazine editor, freelance writer and arts critic, says both methods work. But he also recommends engaging a board of consultants to further refine your writing, design and subject matter. In the long run, these outward searches won't hamper the creative editor. "Quite the

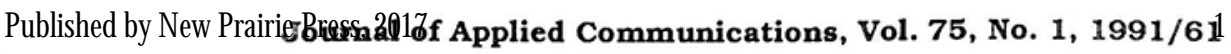




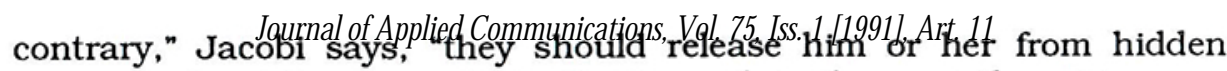
concerns about "Are we really getting through to them out there?"'

Jacobi's art of editing doesn't directly address our problem of limited resources. But it does foster better magazines-publications that give more bang for the buck. A quality magazine, Jacobi implies, follows certain tenets regardless of budget.

Kurt R. Knebusch

Ohio State University

\section{"The Importance of Mechanics in Journalistic Writing: A Study of Reporters and Editors," by Steven A. Ward and Rick Seifert, in Journalism Quarterly, Vol. 67, No. 1, (Spring 1990), pp. 104- 113.}

When they are working on the desk under deadline pressures, editors complain they waste too much time fixing mechanical errors in reporters' copy. Instead they want to concentrate on substantive stylistic and content concerns. At issue is the editor's desire for journalism educators to return to teaching the fundamentals of grammar. Currently, journalism instruction tends to examine the process of writing rather than the product.

The basic question in this debate has rarely been broached, let alone studied: How important is a working knowledge of mechanics to good professional writing? Other questions relating to this subject include: (a) what broad factors form professionals' evaluation of writing?, (b) do editors and reporters agree on their assessments of writing? and (c) what is the relative importance of specific writing abilities to good writing?

Data were gathered from a stratified random sample of 86 reporters and their editors from eight Pacific Northwest daily newspapers. The sample was selected proportionately from small, medium and large papers in Oregon and Washington, all part of the Allied Daily Newspapers chain.

Reporters completed a 100-item, multiple-choice test assessing their knowledge of spelling, parts of speech, punctuation, types of sentences, agreement, case and usage. The test included a section to check reporters' ability to identify problems in sentences.

Reporters' writing abilities were measured four ways:

1. Supervising editors filled out a questionnaire asking for overall ratings of reporters' writing and reporting, as well as rating them in 15 categories of specific writing abilities.

2. Reporters rated themselves on the same questionnaire used by the editors.

3. Reporters listed their writing awards.

4. Reporters listed how often they were complimented on their writing.

Using factor analysis (principal components analysis with varimax rotation), the editors' ratings showed three distinct patterns, or factors.

"Writing mechanics," the first factor, accounted for 29.5 percent of the variance and included the categories of spelling, grammar, punctuation and knowledge of the Associated Press Stylebook. "Expressive ability," the sec-

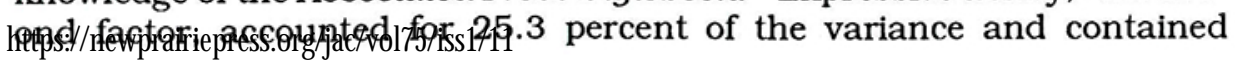


Knebusch and Carlson: The Art of Editing; The Importance of M echanics in Lournalistic W creativity, liveliness, writing style, ease with language and word usage. "Journalistic ability," the third factor, comprised 23.0 percent of the variance. It related to preparing good copy under the journalistic constraints of conciseness, speed in writing, clarity, organization, and self-editing ability.

The reporters' self-ratings were similar to the editors, except for a twoitem shift creating a fourth factor called "job skills," which consisted of speed in writing and knowledge of AP style. Since this factor did not meet the minimum statistical standard for exploratory research, it was discarded.

Test results indicated many reporters lacked knowledge of writing mechanics. Reporters who majored in English as undergraduates did significantly better on the test than reporters who majored in journalism or communications. While editors and reporters generally agreed on the three broad factors used to judge professional writing, reporters tended to rate their expressive and journalistic abilities higher than their editors did.

The four areas used to measure reporters' writing abilities were correlated, revealing several patterns. First, editors' ratings of reporters' writing are highly interrelated. Second, overall ratings of writing are closely associated with expressive writing abilities for both editors and reporters. Third, overall ratings of reporting are closely associated with ratings of journalistic ability. Fourth, ratings of reporters' professional writing are associated with reporters' and editors' ratings of writing mechanics. Fifth, no statistically significant correlation was found between test scores and winning writing awards or receiving compliments.

Educators can best prepare their students by designing all three factors into their curriculums and workshops so they see the connections among mechanical, expressive, and journalistic writing abilities. The authors maintain that journalism educators can use tests of writing mechanics as a valid measure of students' professional writing abilities.

The results of the research come from a limited, homogeneous sample of editors and reporters, all employed by the same newspaper chain. One might argue the editors were employed because they had similar abilities and expectations regarding reporters. The same might be said about the reporters as well. Research on a more heterogeneous group is needed.

Ward and Seifert suggest that future research on good writing might look at corporate communications. Their research suggests ACE members who want to interest/influence editors, must meet the writing criteria editors apply to their reporters. They must know writing mechanics and show both expressive and journalistic ability if they want their news releases published.

Richard P. Carlson

University of Missouri-Columbia

\begin{abstract}
"Trade Show Marketing Idea Kit: A Hands-On Approach for Trade Show Marketers." Available free from Skyline Displays, Inc., 12345 Portland Ave. S, Burnsville, MN 55337. 800-328-2725 (In Minnesota call 612-894-3240.) 50 pages.
\end{abstract}

Getting information on displays and exhibits is difficult. The "Trade Show Marketing Idea Kit" provides an excellent starting point. It's full of Published by New PrairiePress 2017 fourha1 of Applied Communications, Vol. 75, No. 1, 1991/63 3 
practical suggestions and, for me, new and innovative thinking about exhibits.

It is not an advertisement for Skyline Displays, but an compilation of well written articles on planning and organizing for a trade show, generally drawn from Exhibitor Magazine. Although its focus is commercial exhibits, agricultural communicators face opportunities where exhibits might be the appropriate communication medium-fairs, meetings, recruitment, schools, Extension initiatives, and malls.

Organized as part of a course on exhibits and displays, the "Idea Book" bundles such major exhibit concepts as basic planning, getting traffic to the exhibit, and maximizing the entire venture through evaluation with helpful aids. The aids include a 16-week planning cycle and design-planning worksheet; tips for selecting the right show; work forms on organizing the corporate strategy, listing goals and objectives; budgeting; space selection; trade-show direct mail; at-show promotion; exhibit design; lead cards and evaluation techniques.

Did you know strategies exist for selecting the right booth location? "Trade Show Marketing" offers at least ten. Here are some of them:

- the center of influence (the center of the exhibit space) has the most power and being close to the center means exhibit influence;

- follow the leader implies locating on the paths or aisles to the booths of the pacesetters because leaders draw crowds;

- path of least resistance suggests placement of your exhibit on the route to the meeting rooms, meaning that people will pass your display often.

This entire section on exhibit placement was a very stimulating one.

How do you make exhibit design more effective? A very nice section on exhibit ergonomics tells you. The strategy is based on an adult's area of sight-a radiating pattern of 30 degrees up and down, and side-to-side. Exhibit lettering and title placement are based on this 30 degree cone. The author discusses type styles and color preferences, contrast and color, and contrast and legibility, as well as work area ergonomics. Using a speaker within an exhibit to draw an audience is considered as well. This fascinating section was full of new information. It suggests aesthetics often determine an exhibit's look and some general graphics "rules" can and should be broken.

Checklists and forms are plentiful. The reading is easy and lively. The "Trade Show Marketing Idea Kit" is a real pleasure and should be on the shelf of anyone consulting or doing displays.

James W. King

University of Nebraska - Lincoln

\begin{abstract}
"Seeing is Remembering: How Visuals Contribute to Learning from Television News," by Doris A. Graber in Journal of Communication, (Summer 1990); Vol. 40, NO. 3. University of Pennsylvania, Philadelphia, Pennsylvania, pp. 134-155.
\end{abstract}

Effective use of television as a teaching medium may depend on how well

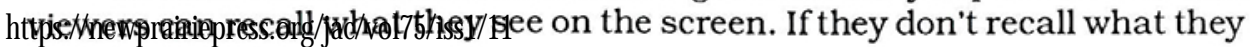
DOl: $10.4148 / 1051-0834.1493$

Journal of Applied Communications, Vol. 75, No. 1, 1991/64 
Knebusch and Carlson: The Art of Editing; The Importance of M echanics in Journalistic W just saw, it seems unlikely that those visuals contribute to their learning. On the other hand, recalling what they saw should help them remember the information presented.

Doris A. Graber, a professor in the Department of Political Science at the University of Illinois at Chicago, studied the types of visuals viewers recalled seeing in television news.

In order, viewers recalled:

- Close-ups of familiar people.

- Close-ups of unfamiliar people in exotic circumstances.

- Close-ups of unfamiliar people who become noteworthy to the audience because they hear them express their views.

Viewers generally failed to recall:

- Stereotypical pictures providing factual information that further clarified the verbal statements. For example, pictures of farms that illustrate areas most affected by the farm crisis or pictures of chemical plants designated as polluters.

- So-called establishing shots that indicate where action is taking place, such as a picture of the Supreme Court building when its decisions are discussed.

- Distant shots of various activities, including crowd actions.

- Vistas of scenes well known from everyday life, such as domestic animals, customers buying gasoline, or scientists handling test tubes.

The research indicated the greatest information gains come from two types of subjects-unusual sights and pictures of people that provide viewers with information they can use to develop reactions to the people in the pictures.

Although Graber's research focused on television news stories, the results can apply to educational television programs and news spots that ACE members produce.

Joyce Patterson

Oregon State University 